\title{
Proceedings
}

Nutrition\& Metabolism

\section{The Discovery of Water Channels (Aquaporins)}

\author{
Dennis Brown \\ Center for Systems Biology and Program in Membrane Biology/Division of Nephrology, \\ Massachusetts General Hospital and Harvard Medical School, Boston, MA, USA
}

\begin{abstract}
Keywords
Water channels · Aquaporins · Kidney · Cell membrane . Water flow · Vasopressin
\end{abstract}

\begin{abstract}
The movement of water into and out of cells is a fundamental biological process that is essential for life. Such water movement not only regulates the activity of individual cells but also is responsible for the functioning of many organ systems and for maintaining whole body water balance. It had long been suspected that water movement across biological cell membranes was in some way enhanced or facilitated by pores or channels, but the search to identify these channels was long and tedious. As is often the case in science, the secret of the water channel was eventually discovered by chance in 1992 by Peter Agre and his colleagues at the Johns Hopkins University in Baltimore, who were working on red blood cell membrane proteins. This "first" water channel was originally named CHIP28 and is now known as aquaporin 1. Agre received the Nobel Prize in Chemistry in 2003 for this discovery. There are currently 13 known aquaporins in mammals, distributed in most tissues, but many more have been identified in lower organisms and in the plant kingdom. The involvement of aquaporins in processes such as urinary concentration and body fluid homeostasis, brain function, glandular secretion, skin hydration, male fertility, hearing, vision, and most important body functions that can be imagined are now all under intense scientific scrutiny. Moreover,
\end{abstract}

\begin{tabular}{ll}
\hline KARGER & $\begin{array}{l}\text { ( } 2017 \text { The Author(s) } \\
\text { Published by S. Karger AG, Basel }\end{array}$ \\
$\begin{array}{l}\text { E-Mail karger@karger.com } \\
\text { www.karger.com/anm }\end{array}$ & $\begin{array}{l}\text { This article is licensed under the Creative Commons Attribution- } \\
\text { NonCommercial-NoDerivatives 4.0 International License (CC BY- } \\
\text { NC-ND) (http://www.karger.com/Services/OpenAccessLicense). } \\
\text { Usage and distribution for commercial purposes as well as any dis- } \\
\text { tribution of modified material requires written permission. }\end{array}$
\end{tabular}

Dennis Brown, $\mathrm{PhD}$

Program in Membrane Biology/Division of Nephrology

Massachusetts General Hospital, Simches Research Center

185 Cambridge Street, Suite 8202, Boston, MA 02114 (USA)

E-Mail brown.dennis@mgh.harvard.edu

defects in aquaporin function have been related to various disease conditions and pathological states. This brief review will discuss their background, discovery, and function in selected bodily processes, especially focusing on hydration.

(c) 2017 The Author(s)

Published by S. Karger AG, Basel

\section{Why Are We Interested in Water Channels?}

The cells that constitute our bodies are mostly made up of water. About $65 \%$ of a cell is water. In terms of total body mass, babies are the most "juicy," being composed of $75 \%$ water; lean adults contain $60 \%$ water, while older adults contain only $50 \%$ water. The bulk of the non-water, dry weight in the body is bone. For comparison, perhaps the most water-replete organism is the lettuce (95\% water), while we humans are comparable to a banana (65\% water). During evolution, cells in all organisms have evolved to work optimally in such an aqueous environment, and significant variations in the cellular content of water will concentrate or dilute their molecular components and prevent normal function. Thus, cells need to regulate the amount of water that enters and leaves through their plasma membrane in order to regulate the cytosolic concentration of solutes, ions, electrolytes, proteins, and nucleic acids. In addition, the amount of water in the extracellular spaces within an organism is also tightly controlled. In humans and other mammals, this tribution of modified material requires written permission. 
includes but is not limited to the blood volume, the interstitial space outside of blood vessels, the cerebro-spinal fluid, aqueous humor in the eye, and glandular secretions.

\section{Why Do We Need Water Channels?}

To deal with constantly changing metabolic demands and surrounding conditions, cells need to exchange water rapidly between their cytoplasm (inside) and the external environment (outside) to maintain a constant volume. This is important for many lower organisms that have developed elaborate mechanisms for cell volume regulation, and usually involves not only water transport but also ion fluxes (mostly $\mathrm{Na}^{+}, \mathrm{K}^{+}$, and $\mathrm{Cl}^{-}$) across membranes to recover from excessive swelling or shrinkage when they are exposed to external fluids of different osmolality (e.g., from salty seawater to dilute rainwater) [1]. While these ion transport mechanisms also exist in mammals, much of the regulatory "homeostatic" function in higher organisms is achieved by maintaining a constant internal environment in which our cells reside - the famous "milieu intérieur" or "the sea inside" defined by Claude Bernard [2]. This is achieved in large part by the action of the kidneys, in coordination with brain sensing of plasma volume and concentration (osmolality), and then reacting by increasing or reducing the amount of water that they release into the urine. This will be discussed in more detail below.

In addition to maintaining cell volume, rapid water exchange across cells enables tissues and organs to secrete and/or absorb water as part of their physiological function. Epithelial cells lining some kidney tubules are especially well adapted to this function, but cells in other organ systems can also regulate transepithelial water movement to allow functionally important processes to occur. For example, the fluids secreted by the pancreas, the bile duct, lachrymal, salivary and mammary glands, as well as the choroid plexus and retinal pigment epithelium, all involve rapid transepithelial water movement.

\section{How Does Water Move into and Out of Cells?}

All of these physiological processes involve water movement across cell membranes. It has long been understood that when most cells are placed in distilled water, they swell considerably and may eventually burst. In contrast, when cells are placed in a salt solution that is more concentrated than the salts and other components within their cytoplasm, they will shrink. This process is due in large part to

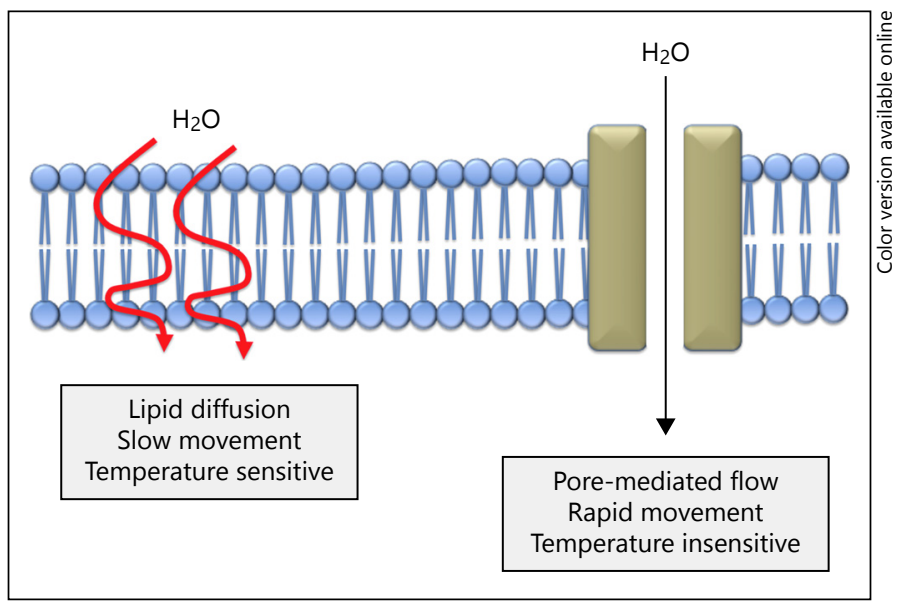

Fig. 1. Pathways by which water can cross a membrane lipid bilayer. Water can diffuse slowly across the bilayer between the lipid molecules (shown in blue). This slow process is highly temperature dependent, similar to most diffusional processes. In contrast, water traverses the membrane much more rapidly through aqueous channels (aquaporins - shown in brown), and this process is much less temperature-sensitive. Aquapoprins allow rapid water movement into and out of cells, which is important for many vital physiological processes, including urinary concentration.

osmotic water flow, up or down a concentration gradient, in an attempt by the system to equilibrate the osmotic concentration on both sides of the cell plasma membrane. But how exactly does water move across the cell membrane? Using a special device that can measure the swelling and shrinking of red blood cells, an experimental model that is easy to obtain and manipulate, researchers concluded that water has 2 pathways across membranes. When osmotic swelling and shrinking were monitored at different temperatures, Solomon [3] discovered a slow, temperaturesensitive process upon which was superimposed a much more rapid temperature-independent process (Fig. 1). The slow process reflected diffusional permeability of water across the fatty lipid bilayer of the plasma membrane - diffusion is temperature sensitive. But the fast process was consistent with the presence of aqueous pores in the membrane, which allowed the more rapid, osmotically driven passage of water that did not involve diffusion (Fig. 1). Macey and Farmer [4] and others then showed that the compound mercuric chloride could significantly inhibit the fast component of this process, which suggested the presence of a protein pore - or water channel - within the membrane. Mercuric chloride binds to sulfhydryl groups (cysteine residues) on proteins and inhibits their function: in this case, water permeability. Thus, this research that focused on red blood cells clearly verified the concept that

\section{Brown}


water pores are responsible for the rapid, temperature insensitive, osmotically driven passage of water across biological membranes. As we shall see, these pores were subsequently identified as the aquaporins.

\section{The Kidney Regulates Our Body Water Content}

The kidney is a remarkable organ that is best known for "filtering" the blood to remove waste products such as urea and other toxins and for producing urine. Approximately $180 \mathrm{~L}$ of blood is filtered each day, yet most individuals produce only about $1.5 \mathrm{~L}$ of urine. The precise amount depends upon how much you drink, how hot it is, and how much you exercise (which causes water loss by sweating). About $90 \%$ of the filtered fluid is removed in proximal regions of the kidney and this value is quite constant in most people. However, the remaining $10 \%$ $(18 \mathrm{~L})$ is reabsorbed in the kidney collecting duct under the influence of the antidiuretic hormone, vasopressin (VP). VP is released by the posterior pituitary gland in response to dehydration (which results in an increase in serum osmotic concentration) or volume loss. It acts on kidney collecting duct epithelial cells via a specific receptor called the vasopressin receptor (V2R) [5] to stimulate water reabsorption, which corrects the problem and restores blood concentration and/or volume to normal levels. The mechanism by which VP causes this fluid uptake across the collecting duct epithelium is now quite well understood and involves aquaporin water channels.

\section{The Toad Urinary Bladder as a Model for the Kidney}

It is worthwhile to take a step back and look at how the mechanism of action of VP was examined experimentally. While the effects of VP on kidney function had been well known for some time, a detailed dissection of its cellular action required a model system that was more accessible than the kidney. It is very difficult (but not impossible) to work with individual kidney tubules, since they are so very small - only about $40 \mu \mathrm{m}$ in diameter. A major breakthrough in research came when Bentley (and others) discovered that the toad urinary bladder also transported water in response to antidiuretic hormone [6]. This is a natural part of their survival process in the wild. When immersed in water, the toad absorbs water through its skin and produces lots of very dilute urine, which it stores in a large, balloon-like bladder. When the toad has limited access to pond water and begins to dehydrate, its own antidiuretic hormone (called vasotocin, an analog of VP) is released and causes the bladder epithelium to become permeable to water. Thus, water stored in the bladder is returned to the blood to rehydrate the creature. In essence, the toad carries its own bottled water around with it in its bladder. The toad urinary bladder thus became a widely used surrogate for examining and understanding VP-induced water flow across the kidney collecting duct epithelium [7].

For many years, the toad bladder was used to examine the onset and offset of VP action on water flow across epithelial cells. Many cellular signaling pathways that regulate this process downstream of the VP-receptor interaction were identified. One of the most intriguing findings that emerged from the many toad bladder studies was the concept of water channels being inserted into the plasma membrane of these epithelial cells in order to increase membrane, and hence epithelial water permeability. Upon hormone withdrawal, these "water channels" would then be removed from the plasma membrane by internalization into the cell (a process known as endocytosis), which restored the membrane to its baseline impermeable state and prevented water flow. This idea was published by Wade [8] who coined the term "shuttle hypothesis" to describe the back and forth movement of water channels to and from the cell surface by analogy with the NASA space shuttle. But the nature of these water channels remained unknown.

\section{The Discovery of Aquaporin Water Channels}

Despite many attempts to identify the protein that formed water channels, the field was essentially frozen in time for many years. All directed attempts to isolate the protein from purified membranes of erythrocytes from toad bladders and from the kidney had met with limited success, although some publications came close [9] and others provided important information, such as information about molecular size (about $30 \mathrm{kD})$ [10]. And so it happened that the Agre group, while looking at Rhesus factor proteins in red cell membranes, noticed a consistent "contaminating" band on their gels at around $28 \mathrm{kD}$ [11]. Rather than discarding this information, they dug a little deeper and concluded that this might be the much sought after water channel in red cells. It was isolated and purified, and antibodies showed that it was also expressed in cells of kidney proximal tubules and the thin descending limb of Henle - both are constitutively highly permeable to water. Could this be the water channel? The defining moment came when the Agre group injected mRNA encoding this protein into an in vitro expression system, Xenopus oo- 
cytes. The oocyte membrane is normally very impermeable to water - the eggs are deposited into fresh water and would burst open if the membrane was permeable! But after injection of mRNA coding for the putative water channel, oocytes dropped into distilled water did exactly that - they burst, while control oocytes remained intact [12]. The Agre group realized that the mRNA they injected had forced the oocytes to produce a new protein which, when moved to the oocyte membrane by cellular transport mechanisms, caused the membrane to become highly permeable to water. Much celebration ensued. A series of subsequent papers confirmed that this new protein, called CHIP28 (channel-forming integral membrane protein of $28 \mathrm{kD}$ ), was the first water channel to be definitively identified [13].

\section{The Aquaporin Family}

Soon after the molecular identity of CHIP28 became known, others found a series of homologous proteins that formed a new family. They became known as aquaporins [14]. At the time the name was first used, there were 4 known aquaporins in mammals - AQP1, 2, 3, and 4. There are now 13 mammalian aquaporins [15], and hundreds have been identified in other organisms, including plants [16]. All these have the same overall structural features, with a molecular weight of about $30 \mathrm{kD}$ in the non-glycosylated form, and several different glycosylation states that result in a higher molecular weight. They all have 6 transmembrane spanning domains; the $\mathrm{C}$ - and $\mathrm{N}$-termini are both in the cytoplasm; they form a functional tetramer in the lipid bilayer and the structure of the water pore within the protein has been elucidated by X-ray crystallography for some of the aquaporins [17]. Unexpectedly, some aquaporins are more water permeable than others, and some can transport other molecules in addition to water. For example, AQP3 is permeable to glycerol, and AQP9 is permeable to urea. In addition, some aquaporins are permeable to gases such as $\mathrm{CO}_{2}[18]$ and $\mathrm{NO}$ [19]. Thus, the field of aquaporin biology is ever expanding, and reports of new and unexpected functions within various cells and tissues continue to emerge on a regular basis.

\section{Aquaporin 1 and 2 (the VP Sensitive Water Channel) in the Kidney}

AQP1, the red cell water channel, is highly expressed in proximal tubules and thin descending limbs of Henle, both of which are highly permeable to water at all times
$[20,21]$. These tubule segments are involved in reabsorbing $90 \%$ of the filtered water. A second aquaporin, AQP2, was identified in collecting duct principal cells of the kidney [22]. These are the cells that (like the toad bladder) change their water permeability in response to the antidiuretic hormone, $\mathrm{VP}$, and thus regulate the reabsorption of the remaining fluid - almost $20 \mathrm{~L}$ per day. AQP2 is the VP-regulated water channel. In the presence of VP, AQP2 accumulates at the surface of principal cells and water traverses the epithelium driven by an osmotic gradient (Fig. 2). The basolateral aspect of these tubules is hypertonic to the fluid in the tubule lumen and water flows downhill along this gradient in the presence of VP. The basolateral membrane of principal cells is always water permeable due to the presence of either AQP3 or AQP4 in different parts of the kidney [23]. Thus, the amount of AQP2 in the apical membrane is the rate-limiting factor that regulates water reabsorption in the kidney collecting duct. Many years of research have shown that AQP2 recycles between the plasma membrane and cytoplasmic vesicles in principal cells, and VP changes the equilibrium such that more AQP2 accumulates at the cell surface and less is inside the cell, accounting for the membrane permeability increase (Fig. 2). The cell biology underlying this process is partially understood, and involves a signaling cascade that is initiated by VP interaction with its receptor, activation of an adenylyl cyclase to increase intracellular cAMP, activation of protein kinase A, and phosphorylation of the AQP2 protein. Phosphorylation is the critical event that causes membrane accumulation of AQP2, and several laboratories are involved in studies aimed at further understanding this process. The interested reader is referred to recent detailed reviews on this process $[23,24]$.

\section{Pathophysiology of Aquaporins}

As might be expected, aquaporins have been implicated in several diseases, most notably in the kidney (Fig. 3). Malfunction or mutations in AQP2 or, more commonly the V2R, cause nephrogenic diabetes insipidus (NDI), in which patients are unable to concentrate their urine and theoretically could void up to $18 \mathrm{~L}$ of dilute urine each day, that is, the amount normally reabsorbed in the collecting duct. Because of other compensatory mechanisms, most patients with NDI produce between 5 and $10 \mathrm{~L}$ per day $[25,26]$. Available therapies can only partially alleviate the symptoms, and more work is required to find better cures. The most
40

Ann Nutr Metab 2017;70(suppl 1):37-42 DOI: $10.1159 / 000463061$
Brown 

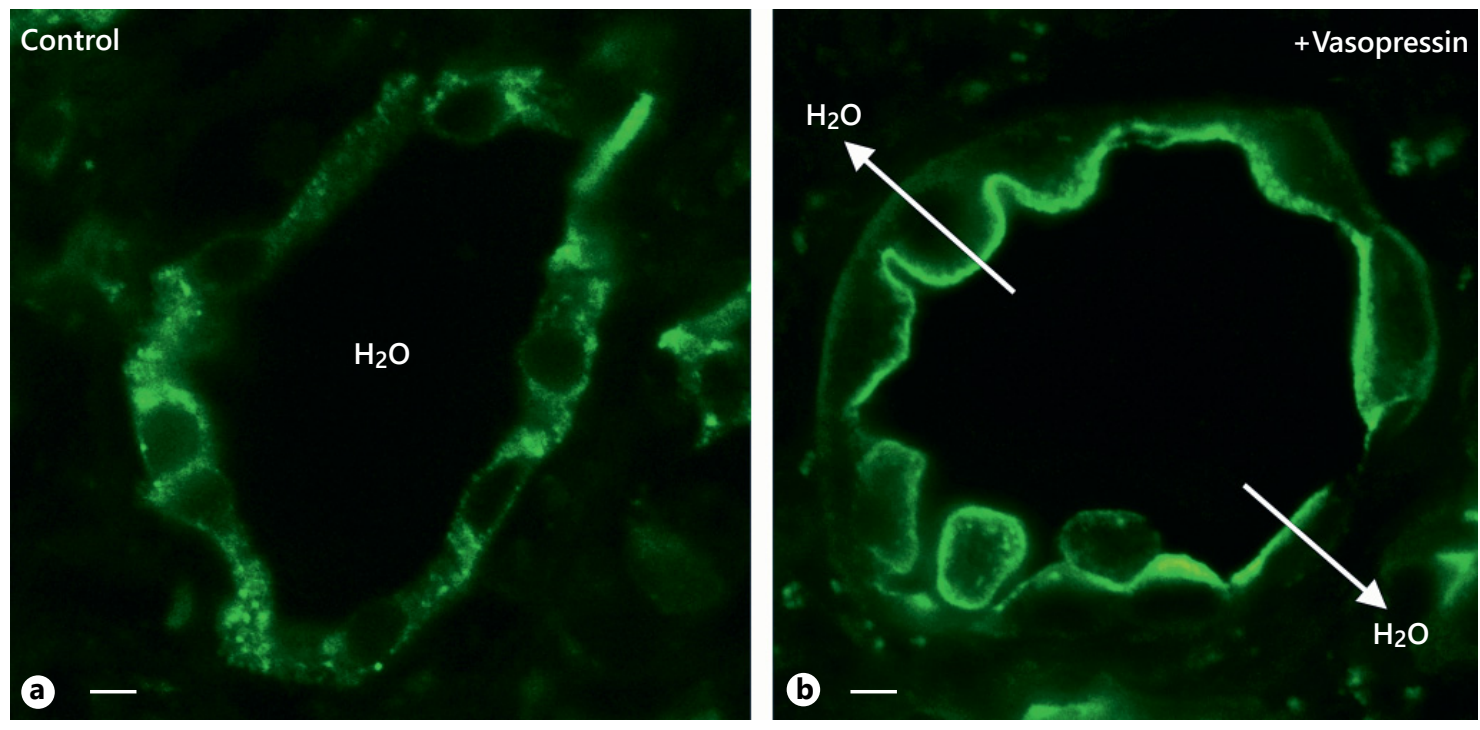

Fig. 2. Tissue sections of kidney collecting duct from a control Brattleboro rat (a) and a rat infused for $30 \mathrm{~min}$ with vasopressin (VP; b), and then immunostained to show the location of the AQP2 water channel (green stain). In control rats, AQP2 is diffusely distributed throughout principal cells lining the collecting duct, and water remains in the tubule lumen. In the VP-treated animals, AQP2 rapidly accumulates in a tight band at the apical membrane of the principal cells, which become permeable and allow water to move out of the lumen, across the cell (arrows) and into the surrounding hypertonic interstitium where it subsequently is recaptured into the circulation via peritubular capillaries. $\operatorname{Bar}=5 \mu \mathrm{m}$.
Fig. 3. Defects in aquaporin 2 expression or trafficking cause a variety of diseases related to water balance. These can be hereditary or acquired. Downregulation of AQP2 membrane accumulation, most commonly due to mutations in the vasopressin receptor (V2R) or AQP2 itself (less frequently) causes nephrogenic diabetes insipidus and the production of large volumes of dilute urine. This disease can also be acquired as a result of a number of other problems, the most common of which is lithium induced nephrotoxicity (see text). In contrast, the inappropriate upregulation of AQP2 in the membrane of collecting duct principal cells occurs in congestive heart failure, cirrhosis, and the syndrome of inappropriate ADH secretion (SIADH). This stimulates excess accumulation of water in the body, resulting in hyponatremia, edema, and hypertension.

common cause of NDI is in patients receiving lithium treatment for bipolar disorder. Lithium causes a severe downregulation of the AQP2 gene for reasons that are not completely understood [27]. While it is a very effective therapy for bipolar disorder, this and other side effects make many patients reluctant to embark on a course of lithium therapy. Other AQP-related disorders, mostly identified in knockout animal models [28],

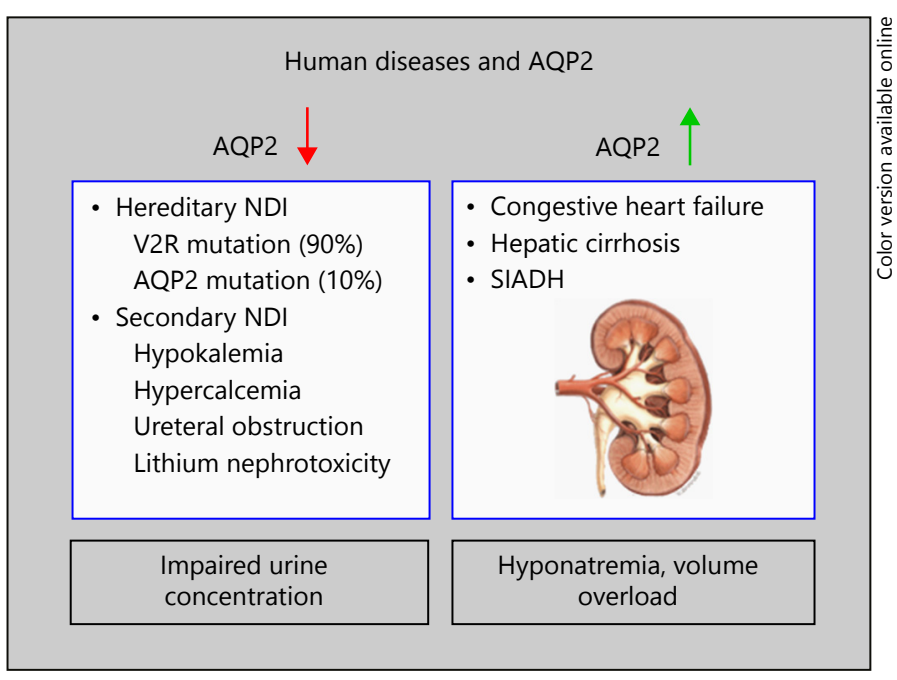

are a urinary-concentrating defect (AQP1 humans have been identified), cataracts (AQP0), stroke (AQP4), and brittle skin due to defective hydration (AQP3). AQP1 and AQP2 have also been implicated in cell migration and wound healing. Finally, the appeal of aquaporins has caught the imagination of advertising agencies involved, for example, in the cosmetic industry. Google it and see! 


\section{Future Directions}

One exciting area of aquaporin biology is the emergence of so-called moonlighting functions of these channel proteins. These can be related to their channel function, as in the case of the gas permeability of AQP1, or unrelated to channel activity as in the case of AQP2, which is involved in kidney development via its interaction with integrins and the extracellular matrix [29]. Future studies will undoubtedly identify more unexpected properties of the aquaporins. A large number of aquaporins are found in non-mammalian "lower" species such as plants, microbes, and fungi. This opens the door to using this information to improve plant growth and adaptation by stimulating AQP function, and to combat microbial and fungal infections by inhibiting aquaporins. Such specific inhibitors are not yet available, but if and when developed, could also have important roles in medicine as aquaretics (to treat hypertension), and per- haps in cancer (to block metastasis). We also have a lot to learn about the cell biology of aquaporin trafficking. How are they moved around in the cell? How do they interact with other proteins? Can alternative signaling pathways be identified and leveraged to bypass defective V2R signaling in NDI? This work is ongoing and promises to reveal cellular secrets that pertain not only to AQP biology but also to other important cellular trafficking events that are implicated in a host of other human diseases.

\section{Acknowledgements/Disclosure Statement}

D.B. and his colleagues in the MGH Program in Membrane Biology have received continuous support for work on aquaporins from the National Institutes of Health, currently grant number DK096586. D.B. received from Danone Research the reimbursement of travel expenses and registration fee to attend the $\mathrm{H} 4 \mathrm{H}$ Scientific Conference.

\section{References}

1 Hoffmann EK, Lambert IH, Pedersen SF: Physiology of cell volume regulation in vertebrates. Physiol Rev 2009;89:193-277.

2 Hoenig MP, Zeidel ML: Homeostasis, the milieu interieur, and the wisdom of the nephron. Clin J Am Soc Nephrol 2014;9:1272-1281.

3 Solomon AK: The permeability of red cells to water and ions. Ann N Y Acad Sci 1958;75: 175-181.

4 Macey RI, Farmer RE: Inhibition of water and solute permeability in human red cells. Biochim Biophys Acta 1970;211:104-106.

5 Lolait SJ, O'Carroll AM, McBride OW, Konig M, Morel A, Brownstein MJ: Cloning and characterization of a vasopressin $\mathrm{V} 2$ receptor and possible link to nephrogenic diabetes insipidus. Nature 1992;357:336-339.

6 Bentley PJ: The effects of neurohypophysial extracts on the water transfer across the wall of the isolated urinary bladder of the toad Bufo marinus. J Endocrinol 1958;17:201-209.

7 Wade JB: Dynamics of apical membrane responses to $\mathrm{ADH}$ in amphibian bladder. Am J Physiol 1989;257(5 pt 2):R998-R1003.

8 Wade JB, Stetson DL, Lewis SA: ADH action: evidence for a membrane shuttle mechanism. Ann N Y Acad Sci 1981;372:106-117.

9 Benga G, Popescu O, Borza V, Pop VI, Muresan A, Mocsy I, et al: Water permeability in human erythrocytes: identification of membrane proteins involved in water transport. Eur J Cell Biol 1986;41:252-262.

10 van Hoek AN, Hom ML, Luthjens LH, de Jong $\mathrm{MD}$, Dempster JA, van Os $\mathrm{CH}$ : Functional unit of $30 \mathrm{kDa}$ for proximal tubule water channels as revealed by radiation inactivation. J Biol Chem 1991;266:16633-16635.
11 Denker BM, Smith BL, Kuhajda FP, Agre P: Identification, purification, and partial characterization of a novel Mr 28,000 integral membrane protein from erythrocytes and renal tubules. J Biol Chem 1988;263:15634-15642.

12 Preston GM, Carroll TP, Guggino WB, Agre $P$ : Appearance of water channels in Xenopus oocytes expressing red cell CHIP28 protein. Science 1992;256:385-387.

13 Agre P: Nobel Lecture. Aquaporin water channels. Biosci Rep 2004;24:127-163.

14 Agre P, Preston GM, Smith BL, Jung JS, Raina S, Moon C, et al: Aquaporin CHIP: the archetypal molecular water channel. Am J Physiol 1993;265(4 pt 2):F463-F476.

15 Ishibashi K: New members of mammalian aquaporins: AQP10-AQP12. Handb Exp Pharmacol 2009;190:251-262.

16 Maurel C, Boursiac Y, Luu DT, Santoni V, Shahzad Z, Verdoucq L: Aquaporins in plants. Physiol Rev 2015;95:1321-1358.

17 Schenk AD, Hite RK, Engel A, Fujiyoshi Y, Walz T: Electron crystallography and aquaporins. Methods Enzymol 2010;483:91-119.

18 Cooper GJ, Occhipinti R, Boron WF: CrossTalk proposal: physiological $\mathrm{CO}_{2}$ exchange can depend on membrane channels. J Physiol 2015;593:5025-5028.

19 Wang Y, Tajkhorshid E: Nitric oxide conduction by the brain aquaporin AQP4. Proteins 2010;78:661-670.

20 Nielsen S, Smith BL, Christensen EI, Knepper MA, Agre P: CHIP28 water channels are localized in constitutively water-permeable segments of the nephron. J Cell Biol 1993;120: 371-383.
21 Sabolic I, Valenti G, Verbavatz JM, Van Hoek AN, Verkman AS, Ausiello DA, et al: Localization of the CHIP28 water channel in rat kidney. Am J Physiol 1992;263(6 pt 1):C1225-C1233.

22 Fushimi K, Uchida S, Hara Y, Hirata Y, Marumo F, Sasaki S: Cloning and expression of apical membrane water channel of rat kidney collecting tubule. Nature 1993;361:549-552.

23 Brown D, Fenton R: The cell biology of vasopressin action; in Taal MW, Chertow GM, Marsden PA, Skorecki K, Yu ASL, Brenner BM (eds): Brenner and Rector's the Kidney. 10. Philadelphia, Elsevier Inc., 2015, pp 281-302.

24 Fenton RA, Pedersen CN, Moeller HB: New insights into regulated aquaporin-2 function. Curr Opin Nephrol Hypertens 2013;22:551558

25 Leroy C, Karrouz W, Douillard C, Do Cao C, Cortet C, Wemeau JL, et al: Diabetes insipidus. Ann Endocrinol (Paris) 2013;74:496-507.

26 Bockenhauer D, Bichet DG: Pathophysiology, diagnosis and management of nephrogenic diabetes insipidus. Nat Rev Nephrol 2015;11: 576-588.

27 Kishore BK, Ecelbarger CM: Lithium: a versatile tool for understanding renal physiology. Am J Physiol Renal Physiol 2013;304:F1139F1149.

28 Verkman AS: Dissecting the roles of aquaporins in renal pathophysiology using transgenic mice. Semin Nephrol 2008;28:217-226.

29 Chen Y, Rice W, Gu Z, Li J, Huang J, Brenner MB, Van Hoek A, Xiong J, Gundersen, GG, Norman JC, Hsu VW, Fenton RA, Brown D, Lu HAJ: Aquaporin 2 promotes cell migration and epithelial morphogenesis. J Am Soc Nephrol 2012;23:1506-1517. 